\title{
ICEQUAKES ON EKSTRÖM ICE SHELF NEAR ATKA BAY, ANTARCTICA (Abstract)
}

\author{
by
}

\section{H. von der Osten-Woldenburg}

(Institut für Allgemeine und Angewandte Geophysik, Ludwig-Maximilians-Universität München, Theresienstrasse 41, D-8000 München 2, Federal Republic of Germany)

Two seismic arrays recorded during an 11 month field experiment in 1985 the seismicity of Ekström Ice Shelf in the area of an ice rumple and an inlet, situated respectively about $10 \mathrm{~km}$ north-west and $7 \mathrm{~km}$ north of the German Antarctic station Georg von Neumayer $\left(70^{\circ} 37^{\prime} \mathrm{S}, 08^{\circ} 22^{\prime} \mathrm{W}\right)$. Most of the focal depths of the icequakes considered until now are in the range $5-9 \mathrm{~m}$, and the ice-rumple area shows extremely high seismic activity. Tensile fracture is the most frequent fault mechanism, although there are a few shear-fracture events. The ice rumple's seismicity provides information on the dynamics of the ice shelf in this area. A comparison of this time-dependent seismicity with tides suggests that most of this seismicity is induced by tides. The most active period of this seismicity starts at the beginning of low tide and ends at low tide. The location of the epicentres of icequakes recorded at that time and the digital recording on tapes of the seismicity without interruption for $396 \mathrm{~h}$ shows a jerky vertical movement of the ice shelf in response to tides; this can be interpreted as a kind of "grater effect", especially at the southern ice-rock boundary of the ice rumple.

The seismicity in the inlet is much less and tensile fracture seems to be the only fault mechanism.

\section{RHEOLOGY OF POLAR GLACIER ICE}

\section{(Abstract)}

Theoretical considerations, laboratory experiments, and inclinometer data support a value $\leqslant 2$ for the exponent of the flow law relating stress and strain-rate in polar ice at low stresses (Pimienta and Duval, 1987). But a value of 3 was deduced from ice-shelf data by Jezek and others (1985). The effect of longitudinal stresses, the development of preferred crystal orientations, or experimental errors explain these discrepancies.

One way of identifying deformation processes of ceramics is to analyze densification rates during isostatic pressure. In polar regions, ice particles sinter under the driving force of the pressure due to the weight of particles deposited on top of them. The final stage of pressure sintering corresponds to the densification of ice with closed spherical pores, i.e. after close-off. At this stage, densification is determined by the creep of the thick spherical shell surrounding each bubble. Surface tensions are

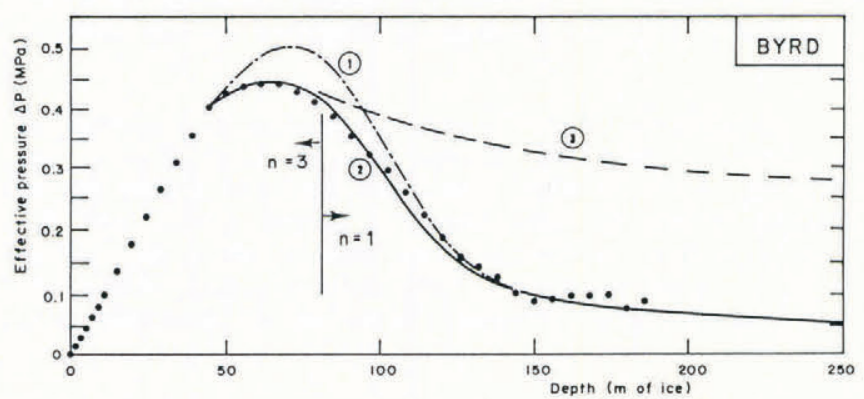

Fig. 1. Variation of effective pressure with depth. Curves 1 and 3 were respectively calculated with $n=1$ and $n=3$. Curve 2 was calculated by taking successively $n=3$ and $n=1$. Experimental points are from Gow (1968). too small to influence the sintering process. The densification rate by power-law creep and by diffusion can be calculated by using models given by Artz and others (1983). Figure 1 shows the evolution of the effective pressure at Byrd Station (Antarctica) below the close-off depth. The power-law creep model was used with $n=3$ and $n=1$. A good fit of the experimental results given by Gow (1968) was obtained by taking successively $n=3$ and $n=1$. On the other hand, the densification rates deduced from the diffusion model are about one order of magnitude lower than experimental values. The quasi-Newtonian behaviour of polar ice at low stresses is therefore supported by this analysis.

Evidence of grain-boundary migration in polar ice from the surface down to bedrock is discussed. Grain growth, driven by grain-boundary energy, is observed in the first $100 \mathrm{~m}$ of ice sheets. At Byrd Station, grain growth ceases at $450 \mathrm{~m}$, whereas it is still observed, at least, down to a depth of $2000 \mathrm{~m}$ at Vostok. Strain energy must be sufficiently small so as not to inhibit this migration process. In the last $100 \mathrm{~m}$ above bedrock, a recrystallization regime involving rapid migration of grain boundaries is observed, if the ice temperature is above $\approx-10^{\circ} \mathrm{C}$. Multi-maxima fabrics are associated with this form of migration recrystallization. At Byrd Station, this regime is observed only below $1800 \mathrm{~m}$. Between these two zones, grain boundaries migrate slowly and grain refinement is achieved via progressive sub-grain rotation. This recrystallization regime is also driven by strain energy and is termed rotation recrystallization (Wilson, 1986). The greater part of ice sheets are involved in this form of recrystallization process.

Both grain-growth and rotation-recrystallization processes are associated with dislocation glide. The rotation of $c$-axes by basal glide appears to be the main mechanism for the formation of fabrics in polar ice (Pimienta and others, 1987). 
Finally, it is shown that dislocation glide is the only mode of deformation in polar ice.

\section{REFERENCES}

Arzt, E., M.F. Ashby, and K.E. Easterling. 1983. Practical applications of hot-isostatic pressing diagrams: four case studies. Metall. Trans., 14A(2), 211-221.

Gow, A.J. 1968. Bubbles and bubble pressures in Antarctic glacier ice. J. Glaciol., 7(50), 167-182.

Jezek, K.C., R.B. Alley, and R.H. Thomas. 1985. Rheology of glacier ice. Science, 227(4692), 1335-1337.
Pimienta, P. and P. Duval. 1987. Rate controlling processes in the creep of polar glacier ice. J. Phys. (Paris), 48, Colloq. C1, 243-248. (Suppl. au 3.)

Pimienta, P., P. Duval, and V. Ya. Lipenkov. 1987. Mechanical behavior of anisotropic polar ice. International Association of Hydrological Sciences Publication 170 (Symposium at Vancouver 1987 - The Physical Basis of Ice Sheet Modelling), 57-66.

Wilson, C.J.L. 1986. Deformation induced recrystallization of ice: the application of in situ experiments. In Hobbs, B.E. and H.C. Heard, eds. Mineral and rock deformation: laboratory studies. Washington, DC, American Geophysical Union, 213-232. (Geophys. Monogr. 36.)

\title{
SURFACE STRAIN-RATES, BYRD GLACIER, ANTARCTICA
}

\section{(Abstract)}

by

John P. Scofield,

(Department of Geological Sciences, University of Maine, Orono, ME 04469, U.S.A.)

Dean R. Lindstrom,

(Department of Geophysical Sciences, University of Chicago, Chicago, IL 60637, U.S.A.)

and

Terence J. Hughes

(Department of Geological Sciences and Institute for Quaternary Studies, University of Maine, Orono, ME 04469, U.S.A.)

A least-squares solution utilizing photogrammetrically determined surface-velocity vectors (Brecher, 1982) was used to compute contour maps of surface strain-rate components on Byrd Glacier. On a broad scale, the results suggest longitudinal extensive flow in the region between 40 and $10 \mathrm{~km}$ above the grounding zone, laminar flow in the vicinity of the grounding zone, and longitudinal compressive flow in the region between 10 and $50 \mathrm{~km}$ below the grounding zone where flow diverges and enters the Ross Ice Shelf. More localized gradients of longitudinal, transverse, and shear strain-rate suggest that flow is influenced by bedrock topography. Strain-rates along a longitudinal ice-thickness profile above the grounding zone support this contention. Relative extension in the transverse and longitudinal directions correlates well in two locations with bedrock highs and increased surface slope, while compression in the transverse and longitudinal directions correlates with a bedrock low and a decrease in the surface slope in another location.

\section{REFERENCE}

Brecher, H.H. 1982. Photographic determination of surface velocities and elevations on Byrd Glacier. Antarct. J. U.S., 17(5), 79-81.

\section{ELECTRICAL RESISTIVITY SOUNDING RELATED TO ICE-CRYSTAL SIZE: A TECHNIQUE FOR PROBING THE HOLOCENE-WISCONSIN BOUNDARY}

\author{
(Abstract) \\ by \\ Sion Shabtaie and Charles R. Bentley \\ (Geophysical and Polar Research Center, University of Wisconsin-Madison, 1215 West Dayton Street, \\ Madison, WI 53706-1692, U.S.A.)
}

The depth of any know time horizon in an ice sheet is a valuable datum against which to check models of surface mass balance and ice dynamics. Where deep cores have been collected, the Holocene/Wisconsin climatic boundary (about 12000 B.P.) can be identified by changes in a large number of physical and chemical parameters. Unfortunately, there are only a few deep bore holes in the polar regions so other methods, such as geophysical techniques, are needed. One potentially powerful technique is electrical resistivity sounding. The resistivity of polar ice is strongly dependent on temperature, and several physical and chemical properties in the ice. By measuring the apparent resistivity of the ice 